\title{
COBALT IONS STIMULATE A FIBROTIC RESPONSE THROUGH MATRIX REMODELLING, FIBROBLAST CONTRACTION AND RELEASE OF PRO-FIBROTIC SIGNALS FROM MACROPHAGES
}

\author{
J. Xu' ${ }^{1}$, A. Nyga ${ }^{2}$, W. Li $^{1}$, X. Zhang ${ }^{1}$, N. Gavara ${ }^{1}$, M.M. Knight ${ }^{1}$ and J.C. Shelton ${ }^{1, *}$ \\ ${ }^{1}$ Institute of Bioengineering, School of Engineering and Materials Science, \\ Queen Mary University of London, London, UK \\ ${ }^{2}$ Institute for Bioengineering of Catalonia, 08028, Barcelona, Spain
}

\begin{abstract}
Many studies report the adverse responses to metal-on-metal (MoM) hip prostheses, with tissues surrounding failed implants prostheses revealing abundant tissue necrosis and fibrosis. These local effects appear to be initiated by metal ions released from the prosthesis causing the secretion of inflammatory mediators. However, little is known about the effects of the metal ions on tissue remodelling and pseudotumor formation, which are also associated with the failure of MoM hip prostheses. The peri-prosthetic soft-tissue masses can lead to pain, swelling, limited range of joint movement and extensive tissue lesion. To elucidate this cellular response, a multidisciplinary approach using both two- and three-dimensional (2D and 3D) in vitro culture systems was employed to study the effects of $\mathrm{Co}^{2+}$ and $\mathrm{Cr}^{3+}$ on human fibroblast activation and mechanobiology.

$\mathrm{Co}^{2+}$ induced a fibrotic response, characterised by cytoskeletal remodelling and enhanced collagen matrix contraction. This was associated with increased cell stiffness and contractile forces, as measured by atomic force microscopy and traction force microscopy, respectively. These effects were triggered by the generation of reactive oxygen species (ROS). Moreover, this fibrotic response was enhanced in the presence of macrophages, which increased the prevalence of $\alpha$-smooth muscle actin ( $\alpha$-SMA)-positive fibroblasts and collagen synthesis. $\mathrm{Cr}^{3+}$ did not show any significant effect on fibroblast activation.

$\mathrm{Co}^{2+}$ promoted matrix remodelling by fibroblasts that was further enhanced by macrophage signalling. Use of alternative implant materials or manipulation of this fibrotic response could provide an opportunity for enhancing the success of prostheses utilising CoCr alloys.
\end{abstract}

Keywords: Cobalt chromium, fibroblast, extracellular matrix, cell mechanics, reactive oxygen species, fibrosis.

*Address for correspondence: J.C. Shelton, Institute of Bioengineering, School of Engineering and Materials Science, Queen Mary University of London, London, UK.

Email: j.shelton@qmul.ac.uk

Copyright policy: This article is distributed in accordance with Creative Commons Attribution Licence (http://creativecommons.org/licenses/by-sa/4.0/).

\section{Introduction}

More than one million metal-on-metal (MoM) hip replacement prostheses made from cobalt chromium (CoCr) alloys are implanted worldwide to restore mobility and improve the quality of life in patients suffering from severe osteoarthritis or femoral fractures (Kwon et al., 2014). MoM total hip replacements are performed in younger and more active patients due to the adverse reactions to polyethylene particles generated in metalon-polyethylene (MoP) bearings (Muller, 1995). However, concerns for the MoM implants become increasingly prominent as adverse reactions to metal debris (ARMD) are widely reported (Matharu et al.,
2016; Shulman et al., 2015). Considerable amounts of $\mathrm{Co}$ and $\mathrm{Cr}$ ions are released into the synovial fluid, with the Co level increasing up to $24,000 \mathrm{ng} / \mu \mathrm{L}$ (approximately $400 \mu \mathrm{M}$ ) in the vicinity of the MoM implants (Davda et al., 2011). Metal ions released into periprosthetic tissues induce cytotoxicity, apoptosis and necrosis, with upregulation of various cytokines and chemokines (Catelas et al., 2001; Fleury et al., 2006; Petit et al., 2004; Queally et al., 2009). The released ions, $\mathrm{CO}^{2+}$ and $\mathrm{Cr}^{3+}$, causing issues when using MoM implants, are also frequently reported in patients with MoP bearings with associated adverse effects, including local tissue reactions and pseudotumour formation (Dimitriou et al., 2016; Jennings et al., 2016; Kwon et al., 2016; Pandit et al., 2008; Plummer et al., 
2016). Histological evaluation of the synovial tissues from revision hips utilising $\mathrm{CoCr}$ alloys frequently reveals an extensive tissue reaction characterised by abundant tissue necrosis and fibrosis with infiltration of immune cells (Campbell et al., 2010). Furthermore, soft tissues - obtained during revision operations - surrounding $\mathrm{CoCr}$ components are frequently characterised by massive infiltration of macrophages (Natu et al., 2012). Although total joint replacements are frequently associated with aberrant tissue remodelling (Campbell et al., 2010; Willert et al., 2005), few published studies investigate how the underlying cellular processes are activated by the release of either Co and Cr ions (Madl et al., 2015). Understanding these mechanisms could provide a new means of controlling implant-induced fibrosis and matrix remodelling with the aim of enhancing implant performance.

Investigations of the biological response to implant metal debris and released ions are largely based on cytotoxicity (Behl et al., 2013; Dalal et al., 2012; Papageorgiou et al., 2007), with some studies utilising immune cells to examine the profile of secreted cytokines in response to $\mathrm{Co}$ and $\mathrm{Cr}$ (Madl et al., 2015). However, few studies examine the subtoxic effect on fibroblasts, which are responsible for the synthesis and maintenance of the collagenous extracellular matrix (ECM) (Papageorgiou et al., 2007). Accordingly, the current study was designed to examine the effect of $\mathrm{Co}$ and $\mathrm{Cr}$ ions on the activity of fibroblasts in the form of the mechanical integrity of the ECM. In order to reproduce the synergies between fibroblasts and macrophages in the periprosthetic tissue, the influence of macrophages on the fibrotic response of fibroblasts in the presence of $\mathrm{Co}$ and $\mathrm{Cr}$ was also examined.

\section{Materials and Methods}

\section{Preparation of $\mathrm{Co}^{2+}$ and $\mathrm{Cr}^{3+}$ solutions}

$0.1 \mathrm{M}$ stock solutions of $\mathrm{Co}^{2+}$ and $\mathrm{Cr}^{3+}$ were freshly prepared by dissolving $\mathrm{CoCl}_{2} \cdot 6 \mathrm{H}_{2} \mathrm{O}(99.5 \%$ purity; Sigma-Aldrich) and $\mathrm{CrCl}_{3} \cdot 6 \mathrm{H}_{2} \mathrm{O}(98 \%$ purity; SigmaAldrich) in sterile $\mathrm{H}_{2} \mathrm{O}$. These solutions were sterilised by filtration through $0.2 \mu \mathrm{m}$ pore size sterile syringe filter (Merck Millipore). Stock solutions of $\mathrm{Co}^{2+}$ and $\mathrm{Cr}^{3+}$ were further diluted in cell culture medium to achieve the required experimental concentrations of 100-500 $\mu \mathrm{M}$ for $\mathrm{Co}^{2+}$ and $100-800 \mu \mathrm{M}$ for $\mathrm{Cr}^{3+}$.

\section{Primary culture of human fibroblasts and U937 cells}

All cells were maintained at $37^{\circ} \mathrm{C}$ in $5 \% \mathrm{CO}_{2}$ in a humidified atmosphere using the appropriate cell culture medium.

\section{Human dermal fibroblasts (HDFs)}

Normal adult HDFs (PromoCell, UK) were grown in Dulbecco's modified Eagle medium (DMEM) (4.5 g/L glucose, Gibco) supplemented with $10 \%$ foetal calf serum (FCS), $0.625 \mu \mathrm{g} / \mathrm{mL}$ amphotericin, $100 \mathrm{IU} / \mathrm{mL}$ penicillin and $100 \mu \mathrm{g} / \mathrm{mL}$ streptomycin (all from Sigma-Aldrich). The medium was changed every $3 \mathrm{~d}$ until the cells reached $80 \%$ confluency. HDFs between passages 3 and 8 were used for the experiments.

\section{U937 cell line}

The U937 cell line (passage 6-25, donation from Dr Akihisa Mitani, Imperial College, London, UK) were cultured in Roswell Park Memorial Institute (RPMI) 1640 medium [1.9 mM L-glutamine, 19 mM 4-(2-hydroxyethyl)-1-piperazineethanesulfonic acid (HEPES); ThermoFisher Scientific] supplemented with $10 \%$ foetal bovine serum (FBS, Sigma-Aldrich), $100 \mathrm{IU} / \mathrm{mL}$ penicillin and $100 \mu \mathrm{g} / \mathrm{mL}$ streptomycin. To induce differentiation into adherent macrophage-like cells, U937 cells were treated with $50 \mathrm{ng} / \mathrm{mL}$ phorbol 12-myristate 13-acetate (PMA, Sigma-Aldrich) for $48 \mathrm{~h}$. This was followed by a $24 \mathrm{~h}$ rest period in complete RPMI 1640 medium prior to further experiments.

\section{Co-culture}

Porous plasma-treated polycarbonate inserts (pore size: $3 \mu \mathrm{m}$; Transwell, Corning) were used for noncontact co-culture of fibroblasts. HDFs were cultured at $0.4 \times 10^{5}$ cells/well and U937 macrophages at $2 \times 10^{5}$ cells/well in 24 -well tissue culture plates. Cells were added to the upper chamber of the Transwell ${ }^{\circledR}$ (Costar) insert, providing a co-culture within each well.

\section{Three-dimensional (3D) culture}

Rat tail collagen type I ( $2 \mathrm{mg} / \mathrm{mL}$, FirstLink, Wolverhampton, UK) was used to fabricate a 3D matrix by collagen fibril self-assembly. The solution containing collagen $(1 \mathrm{mg} / \mathrm{mL})$ and $10 \times$ minimum essential medium (MEM) (ThermoFisher Scientific) was adjusted to pH 7.4 using $1 \mathrm{M} \mathrm{NaOH}$. A cell suspension was added and the cell-containing collagen mixture was polymerised at $37^{\circ} \mathrm{C}$ for $30 \mathrm{~min}$ in cell culture plates to create a final cell density of $2 \times 10^{5}$ cells/mL. Serum-free DMEM medium was subsequently added to each well.

\section{Cell viability and proliferation test}

A LIVE-DEAD ${ }^{\mathrm{TM}}$ Viability/Cytotoxicity Kit (ThermoFisher Scientific) was used to measure cell viability in the presence of $\mathrm{Co}$ and $\mathrm{Cr}$ ions. HDFs in 96-well tissue culture plates $\left(5 \times 10^{3}\right.$ cells/well for $2 \mathrm{D}$ and $2 \times 10^{4}$ cells/well for 3D cultures) were exposed for $6 \mathrm{~h}$ to 200,300 or $500 \mu \mathrm{M} \mathrm{Co}^{2+}$ or 200,400 or $800 \mu \mathrm{M}$ $\mathrm{Cr}^{3+}$. Following exposure, supernatants were removed and a $200 \mu \mathrm{L}$ solution of $1 \mu \mathrm{M}$ calcein AM and $2 \mu \mathrm{M}$ ethidium homodimer in phosphate-buffered saline (PBS) was added to each well for $20 \mathrm{~min}$. Then, fluorescence images were captured using a $\times 10$ magnification on a SP2 confocal microscope. Viable cells were stained green with calcein AM (excitation $495 \mathrm{~nm}$, emission $530 \pm 12.5 \mathrm{~nm}$ ), dead cells red with 
ethidium homodimer (excitation $528 \mathrm{~nm}$, emission $645 \pm 20 \mathrm{~nm}$ ). Three replicates of each condition were tested, with the assay repeated in three separate experiments.

HDF proliferation was measured using CellTiter $96^{\circledR} \mathrm{AQ}_{\text {ueous }}$ One Solution Cell Proliferation Assay (MTS assay, Promega), according to the manufacturer's instructions. HDFs in 96-well tissue culture plates $\left(5 \times 10^{3}\right.$ cells/well for $2 \mathrm{D}$ and $2 \times 10^{4}$ cells/well for 3D cultures) were exposed for up to $96 \mathrm{~h}$ to $100-500 \mu \mathrm{M}$ $\mathrm{Co}^{2+}$ or $100-800 \mu \mathrm{M} \mathrm{Cr}{ }^{3+}$. Following exposures, supernatants were aspirated and $100 \mu \mathrm{L}$ of serum-free DMEM medium containing $10 \%$ CellTiter $96^{\circledR} \mathrm{AQ}_{\text {ueous }}$ One Solution Cell Proliferation reagent were added to each well. Plates were incubated for $2 \mathrm{~h}$ at $37^{\circ} \mathrm{C}$ and the absorbance was measured at $490 \mathrm{~nm}$ using an Infinite F50 plate reader (Tecan). Five replicates of each exposure were tested and the assay was repeated in three separate experiments. Cell viability was determined as the percentage of the control cell viability.

\section{$3 \mathrm{D}$ collagen gel assays}

\section{Collagen gel contraction}

To measure fibroblast-induced collagen contraction, $0.5 \mathrm{~mL}$ of fibroblast-containing collagen solution was added to 24-well cell culture plates and polymerised for $30 \mathrm{~min}$ at $37{ }^{\circ} \mathrm{C}$. Then, $0.5 \mathrm{~mL}$ of serum-free cell culture medium was added and the gels were incubated for $12 \mathrm{~h}$. Following the incubation, gels containing fibroblasts were gently detached from the wells using fine straight and curved forceps. The medium was aspirated and replaced with culture medium containing $\mathrm{Co}^{2+}(100,200$ or $300 \mu \mathrm{M})$ or $\mathrm{Cr}^{3+}(100,200$ or $400 \mu \mathrm{M})$. The gel contraction was recorded by time-lapse imaging over a $6 \mathrm{~h}$ time frame.

\section{Collagen gel stiffness}

Gel stiffness was evaluated for untreated samples or samples exposed to $200 \mu \mathrm{M} \mathrm{Co}^{2+}$ as described in the previous section. Shear rheology of fibroblastcontaining gels was measured with a strain rotational rheometer (T.A. Instruments, New Caste, UK). Storage modulus was measured over a strain range of $0.2-2 \%$ at a fixed angular frequency of $0.5 \mathrm{rad} / \mathrm{s}$ and a temperature of $21^{\circ} \mathrm{C}$.

\section{Immunofluorescence}

Co/Cr-treated fibroblasts were fixed with $4 \%$ paraformaldehyde (Sigma-Aldrich), washed and permeabilised with $0.5 \%$ Triton X-100 (SigmaAldrich) and rinsed 3 times with PBS. Non-specific binding sites were blocked with $1 \%$ bovine serum albumin (BSA) in PBS. Cells were labelled for $\alpha$-smooth muscle actin ( $\alpha$-SMA) by incubation overnight at $4{ }^{\circ} \mathrm{C}$ with a mouse monoclonal anti$\alpha$-SMA primary antibody (1:400, Abcam). Then, cells were washed and incubated for $1 \mathrm{~h}$ at room temperature in Alexa 488 conjugated anti-mouse IgG as a secondary antibody $(1: 1000$, ThermoFisher Scientific). To label the cellular F-actin, fixed fibroblasts in collagen gel were incubated for $30 \mathrm{~min}$ with $200 \mu \mathrm{L}$ of rhodamine-conjugated phalloidin (Molecular Probes) in a humidified chamber at room temperature in the dark. Before imaging, cell nuclei were stained by incubation with $5 \mu \mathrm{g} /$ $\mathrm{mL}$ 4',6-diamidino-2-phenylindole (DAPI; Dojindo, Rockville, MD, USA) followed by three PBS rinses. Slides were visualised with a fluorescence microscope (Leica SP2) utilising a $\times 10$ and $\times 63$ objective.

\section{Transwell ${ }^{\circledR}$ cell migration assay}

Cell migration was investigated using $6.5 \mathrm{~mm}$ Transwell ${ }^{\circledR}$ chambers with $8 \mu \mathrm{m}$ pores (Costar). Briefly, $5 \times 10^{4} \mathrm{HDF}$ in serum-free DMEM were added to the upper chamber of the insert. The lower chamber was filled with $600 \mu \mathrm{L}$ of DMEM supplemented with $10 \%$ FBS to encourage cell migration towards the FBS chemotactic gradient. Cell migration was analysed over a $6 \mathrm{~h}$ period in the presence of $200 \mu \mathrm{M} \mathrm{Co}^{2+}$ in the medium. After $6 \mathrm{~h}$, the migrated cells attached to the bottom surface of the insert were fixed, stained with crystal violet and counted with an inverted microscope utilising a $\times 10$ objective.

\section{Atomic force microscopy (AFM)}

The stiffness of HDFs was measured by AFM(Kreplak, 2006) using the Advanced Quantitative Imaging mode on a JPK NanoWizard 4 system (Bruker Nano GmbH, Berlin, Germany) in combination with an inverted microscope (Axio Observer Z1, Zeiss). Cantilevers (HYDRA6R, AppNano, Mountain View, CA, USA) were calibrated by measuring the sensitivity against a stiff polystyrene substrate and fitting the resonance peak in the thermal noise spectrum to determine the spring constant (approximately $0.08 \mathrm{~N} / \mathrm{m}$ ). A region of interest of $100 \times 100 \mu \mathrm{m}$ was selected to cover an entire cell. Indentations were performed in a format of $32 \times 32 \mu \mathrm{m}$ at a loading/unloading speed of $50 \mu \mathrm{m} / \mathrm{s}$, which minimised cell movement during scanning without compromising the resolution. All the AFM experiments were carried out at $37{ }^{\circ} \mathrm{C}$ in FBS-free medium. Force-indentation curves were further processed in JPK data processing software, which involved background subtraction, height correction and fitting with a modified Hertzian model. A Poisson's ratio of 0.5 was assumed. Young's modulus ranging from $1 \mathrm{kPa}$ to $100 \mathrm{kPa}$ were extracted and a mean value determined to estimate the overall stiffness of a cell.

\section{Traction force measurement}

$22 \mathrm{~mm}$ coverslips (Corning) were treated with hexamethyldisilazane (HMDS, VWR) overnight, rinsed in distilled water and air-dried. A gel solution of $5 \%$ containing acrylamide (Biorad), $0.25 \%$ bis-acrylamide (Biorad), $0.05 \%$ ammonium persulphate (10\% APS stock, Sigma-Aldrich), $0.1 \%$ 1, 2-Bis (dimethylamino) ethane (TEMED, Sigma-Aldrich) and carboxylate-modified beads (fluorescent red, diameter $0.2 \mu \mathrm{m}, 1 \%$ volume 
concentration, ThermoFisher Scientific) was applied to the hydrophobic coverslips. After $15 \mathrm{~min}$ polymerisation at room temperature, the gel was activated under UV light for $30 \mathrm{~min}$ with $1 \mathrm{mg} / \mathrm{mL}$ of the heterobifunctional cross-linker Sulfo-SANPAH (Sigma-Aldrich) and rinsed 5 times with distilled water. Then, the gels were coated with $0.2 \mathrm{mg} / \mathrm{mL}$ type I rat tail collagen. Fibroblasts at a density of $3 \times 10^{4}$ cells/well were plated on the coverslips in a serum-free DMEM and subjected to Co treatment $(200 \mu \mathrm{M})$ for $6 \mathrm{~h}$ prior to imaging (LS720 Microscope, Lumascope) in a humid incubator. Bright-field and $525 \mathrm{~nm}$ image stacks were acquired at each position. After imaging, fibroblasts were lysed with $1 \%$ sodium dodecyl sulphate (SDS) with positions re-imaged. A custom-built analysis pipeline implemented in LabVIEW (National Instruments, Austin, TX, USA) was used to measure the traction forces as previously described (Gavara et al., 2006).

\section{ROS measurement}

ROS formation was measured using 5-(and 6-)-chloromethyl-2'7'-dichlorodihydrofluorescein diacetate (CM-H $\mathrm{H}_{2} \mathrm{DCFDA}$, ThermoFisher Scientific). HDFs in collagen gels $\left(2 \times 10^{4}\right.$ cells/gel $)$ were cultured in black 96-well cell culture plates with a clear bottom. After $6 \mathrm{~h}$ exposure to $100-300 \mu \mathrm{M} \mathrm{Co}^{2+}$, the supernatant was aspirated and the cells were washed with warm PBS. $1 \mu \mathrm{M}(100 \mu \mathrm{L}) \mathrm{CM}-\mathrm{H}_{2}$ DCFDA in Hanks' balanced salt solution (HBBS) was added to the gels that were subsequently incubated for $30 \mathrm{~min}$ at $37{ }^{\circ} \mathrm{C}$ in the dark. Fluorescence was measured at an excitation of $485 \pm 20 \mathrm{~nm}$ and an emission of $528 \pm 20 \mathrm{~nm}$ using a microplate reader (BMG Nova Star, BMG LABTECH, Aylesbury, UK).

\section{Hydroxyproline collagen assay}

To measure the amount of hydroxyproline released in the cell culture medium, HDFs were exposed for $24 \mathrm{~h}$ to $200 \mu \mathrm{M} \mathrm{Co}^{2+}$ or $400 \mu \mathrm{M} \mathrm{Cr}^{3+}$ with or without the presence of U937 macrophages. The culture medium was collected and hydrolysed in $6 \mathrm{~N} \mathrm{HCl}$ for $24 \mathrm{~h}$ at $105{ }^{\circ} \mathrm{C}$. The amount of 4-hydroxyproline in the hydrolysate was determined at a wavelength of $570 \mathrm{~nm}$ with a microplate reader (BMG Nova Star, BMG LABTECH) using the conventional colorimetric method (Reddy and Enwemeka, 1996).

\section{Protein extraction and immunoblotting}

All lysis buffers were supplemented with $1 \%$ protease inhibitor (Sigma-Aldrich). Protein extracts were resolved using gradient precast SDS-polyacrylamide gel electrophoresis (Biorad) and electro-transferred onto a nitrocellulose membrane by using Trans-Blot ${ }^{\circledR}$ Turbo $^{\text {TM }}$ Transfer System (Biorad) for immunoblot analysis. Antibody probing was performed as per manufacturers' instructions. Anti-myosin light chain (MLC) (phospho S20) antibody (1 : 1,000, Abcam) and anti-GAPDH antibody (1:2,000, Abcam) were used. Secondary antibodies, either IRDye ${ }^{\circledR} 800 \mathrm{CW}$ goat anti-mouse IgG (LI-COR) or IRDye ${ }^{\circledR} 800 \mathrm{CW}$ goat anti-rabbit IgG (LI-COR), were used with dilution of $1: 10,000$. Specific protein bands were detected using Odyssey $^{\circledR}$ CLx Imaging System (LI-COR).

\section{Data analysis and statistics}

All data were expressed as the mean \pm standard error of the mean (SEM) of at least three independent experiments. Statistical differences between control and experimental groups were analysed with MannWhitney U test (SPSS Inc). A value of $p<0.05$ was considered to be statistically significant.

\section{Results}

\section{Effect of $\mathrm{Co}^{2+}$ and $\mathrm{Cr}^{3+}$ on human dermal fibroblasts viability and proliferation}

The viability and proliferation of HDFs in the presence of either $\mathrm{Co}^{2+}$ and $\mathrm{Cr}^{3+}$ was assessed in both 2D and 3D gel cultures. Following $6 \mathrm{~h}$ of exposure, both $\mathrm{Co}^{2+}(200-500 \mu \mathrm{M})$ and $\mathrm{Cr}^{3+}(200-800 \mu \mathrm{M})$ yielded minimal effects on the cell viability in either $2 \mathrm{D}$ or 3D (Fig. 1a, quantification of cell viability following treatment are not shown). The effect of $\mathrm{Co}^{2+}$ and $\mathrm{Cr}^{3+}$ on the proliferative capacity of fibroblasts in 2D, investigated by using a CellTiter MTS cell proliferation assay, showed that $\mathrm{Co}^{2+}$ had no obvious effects on fibroblast proliferation over the first $24 \mathrm{~h}$ of treatment (Fig. 1b). After $48 \mathrm{~h}$ of exposure, 100, 200 and $300 \mu \mathrm{M} \mathrm{Co}^{2+}$ transiently increased (although the increase was not statistically significant) the number of fibroblasts by around 5,5 and $8 \%$, respectively, before returning to control levels. However, this effect was not seen when fibroblasts were subjected to $\mathrm{Co}^{2+}$ in 3D collagen matrices (Fig. 1c). In addition, $500 \mu \mathrm{M} \mathrm{Co}{ }^{2+}$ significantly decreased the fibroblast proliferation by around $20 \%$ when compared with untreated cells at 48 and $72 \mathrm{~h} .300$ and $500 \mu \mathrm{M} \mathrm{Co}^{2+}$ also supressed cell proliferation in 3D collagen matrices after $72 \mathrm{~h}$ (Fig. 1c). By contrast, $\mathrm{Cr}^{3+}$ at concentrations ranging from 200 to $800 \mu \mathrm{M}$ had no statistically significant effect on fibroblast proliferation over $72 \mathrm{~h}$ of treatment (Fig. 1d,e). Based on these results, the effects of $\mathrm{Co}^{2+}$ and $\mathrm{Cr}^{3+}$ on fibroblast behaviour were investigated by using $200 \mu \mathrm{M} \mathrm{Co}^{2+}$ and $400 \mu \mathrm{M} \mathrm{Cr}^{3+}$, which had no significant effect on either fibroblast viability or proliferation.

\section{Remodelling of HDF-seeded collagen gels following exposure to $\mathrm{Co}^{2+}$}

To investigate the direct impact of $\mathrm{Co}^{2+}$ on fibroblast functionality, fibroblasts were cultured in type I collagen gels and their morphology was evaluated following $6 \mathrm{~h}$ exposure to either $200 \mu \mathrm{M} \mathrm{Co}^{2+}$ or $400 \mu \mathrm{M} \mathrm{Cr}{ }^{3+}$. Treatment with $\mathrm{Cr}^{3+}$ had no detectable effect on fibroblast morphology, with cells retaining an elongated spindle-like appearance within the collagen matrices, similar to that of untreated cells. By contrast, $\mathrm{Co}^{2+}$ treatment caused a contracted 
a

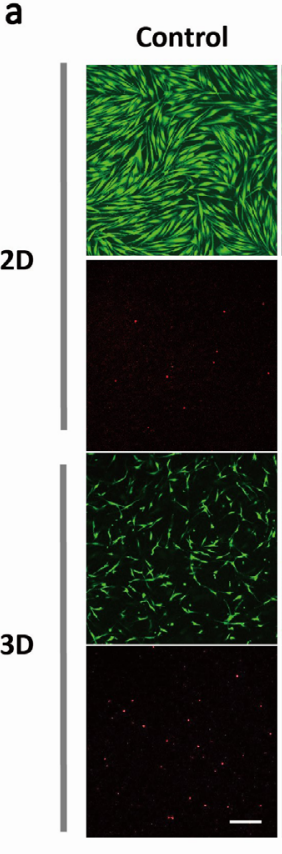

b

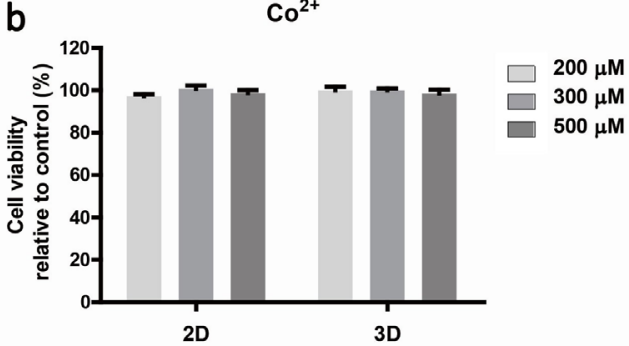

d
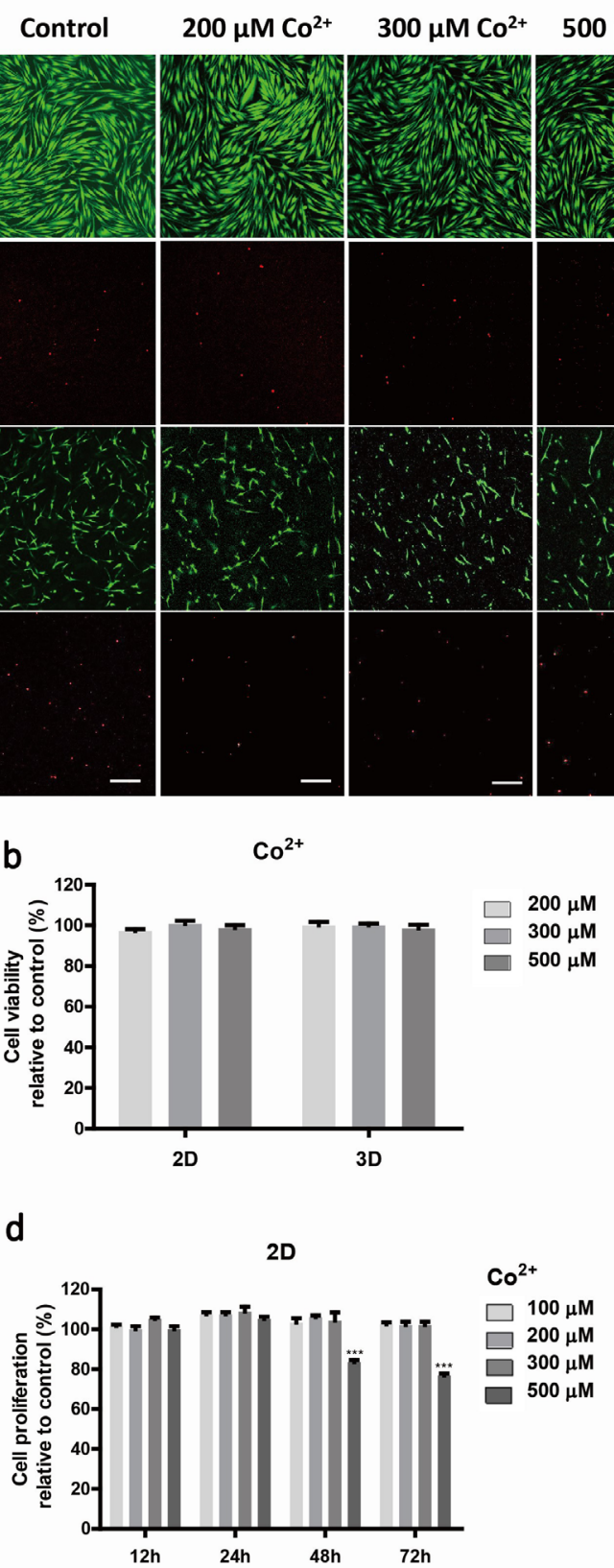
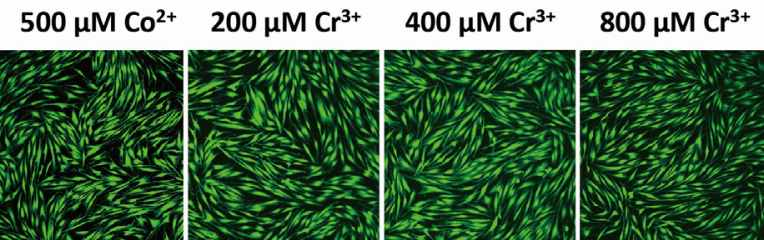

ㅈ.
$\frac{\Phi}{\bar{D}}$
$\frac{\Phi}{\bar{n}}$
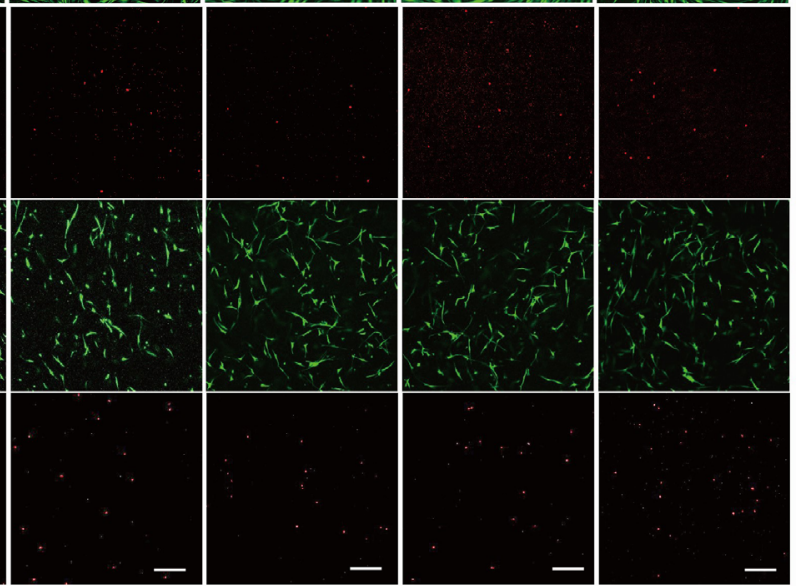

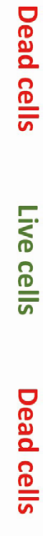

C

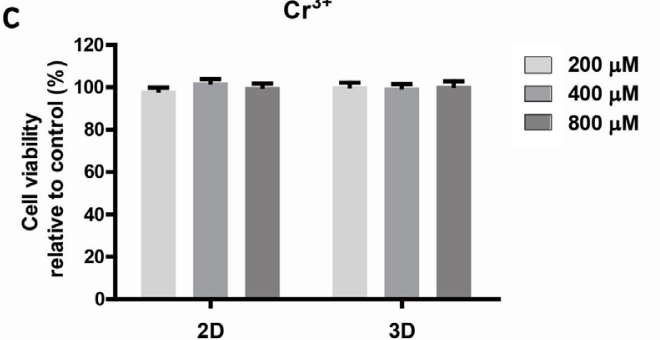

e

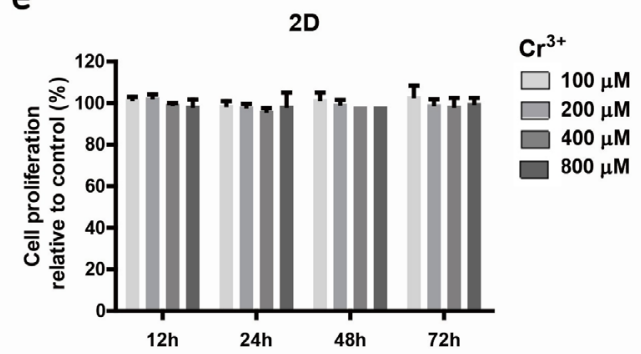

Fig. 1. HDFs viability and proliferation assessed by live/dead assay and MTS assay. (a) Representative fluorescence images showing staining of live (green) and dead (red) cells in 2D and 3D culture following exposure to $\mathrm{Co}^{2+}$ and $\mathrm{Cr}^{3+}(20 \times$ magnification; scale bar: $100 \mu \mathrm{m})$. The effect of $(\mathbf{b}, \mathbf{c}) \mathrm{Co}^{2+}$ and $(\mathbf{d}, \mathbf{e}) \mathrm{Cr}^{3+}$ on HDFs proliferation capacity when grown in 2D tissue culture plates or 3D collagen matrices. Data represent mean + SEM, $n=9$ from 3 independent experiments, with 5 replicates for each condition. Mann-Whitney $\mathrm{U}$ test was used to compare differences between control and treated group; ${ }^{*} p<0.05 ;{ }^{* * *} p<0.001$.

morphology, with an increased formation of actin stress fibres (Fig. 2a) and a reduced fibroblast length (Fig. 2b).

Next, the effect of Co on the fibroblasts' ability to contract and remodel their surrounding matrix was investigated. Over $6 \mathrm{~h}$ of exposure, $\mathrm{Co}^{2+}$ enhanced collagen gel contraction in a time-dependent manner whilst untreated cells showed a negligible contraction (Fig. 2c,d): the collagen gels were contracted by nearly $50 \%$ within the first hour following exposure to $\mathrm{Co}^{2+}(100-300 \mu \mathrm{M})$. The higher dose of $\mathrm{Cr}^{3+}(300 \mu \mathrm{M})$ triggered a more rapid contraction of the collagen matrices with significant differences at $30 \mathrm{~min}$ as compared to $100 \mu \mathrm{M} \mathrm{Co}^{2+}$. By contrast, $100-400 \mu \mathrm{M}$ $\mathrm{Cr}^{3+}$ treatment showed no statistically significant effect on collagen gel contraction (Fig. 2c,d, data only shown for $400 \mu \mathrm{M} \mathrm{Cr}^{3+}$ ). The storage modulus of the cell-seeded collagen gels was independent of the strain magnitude (Fig. 2e). Cells treated for $6 \mathrm{~h}$ with $200 \mu \mathrm{M} \mathrm{Co}^{2+}$ remodelled their collagen matrix resulting in a statistically significant increase in storage modulus from a mean value of $6.9 \pm 0.74 \mathrm{~Pa}$ in untreated constructs to $12.5 \pm 1.3 \mathrm{~Pa}$ in treated constructs (Fig. 2f). $\mathrm{Cr}^{3+}$ had no significant effect on 
a

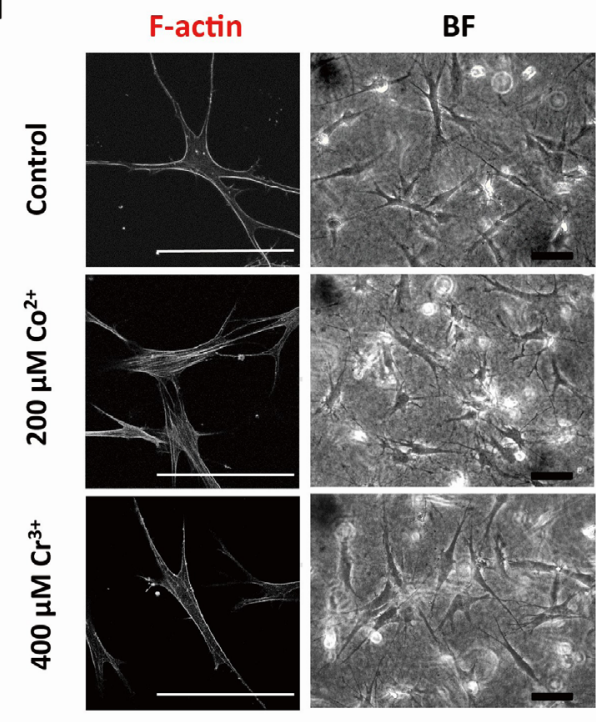

C

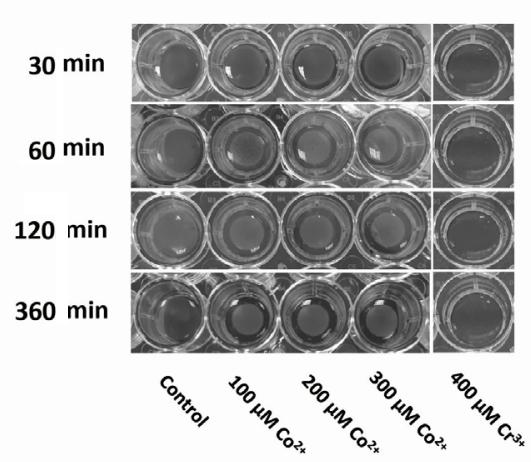

d b
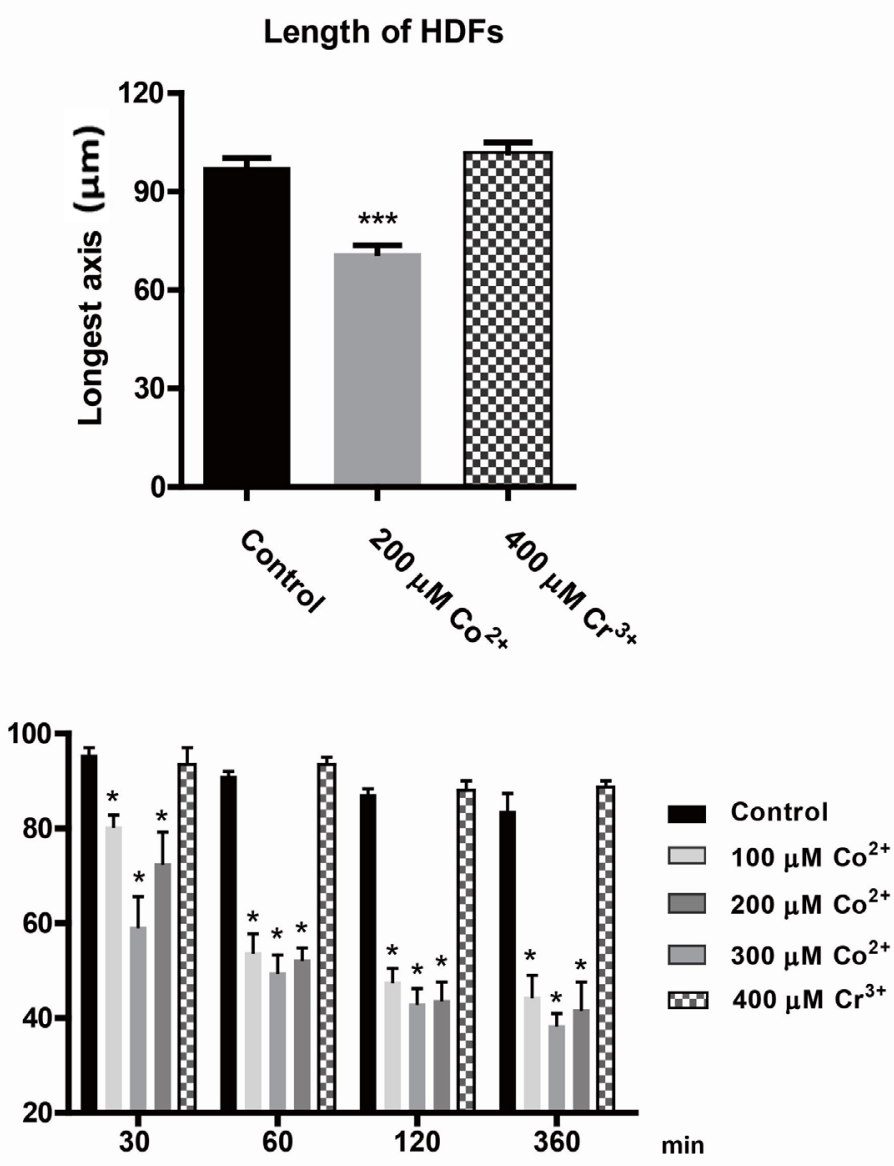

e

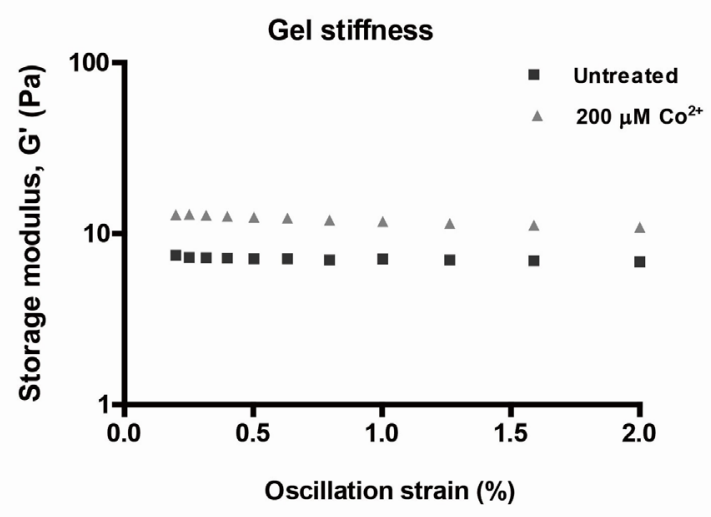

f

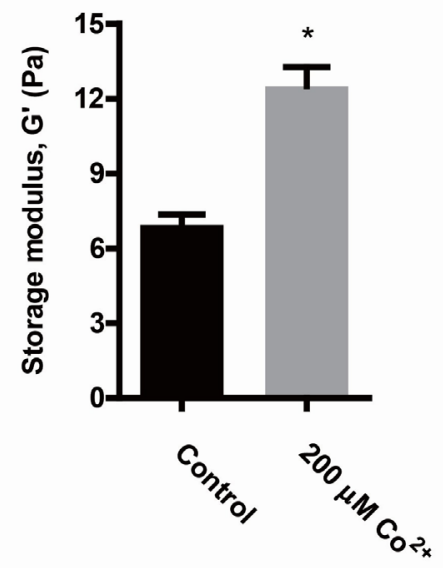

Fig. 2. $\mathrm{Co}^{2+}$ triggered fibroblasts-populated collagen gel remodelling. (a) F-actin staining of human fibroblasts grown in 3D collagen gels; scale bar: $100 \mu \mathrm{m}$. (b) Bars show quantification of the longest distance of fibroblast grown in 3D collagen gels. Bars represent mean + SEM; $n=50$ individual cells from three experimental repeats. Mann-Whitney U test was used to compare differences between control and treated group; ${ }^{* * *} p<0.001$. (c) HDFs-induced gel contraction assay. Images show HDFs-induced contraction of collagen I matrices remodelling over $6 \mathrm{~h}$ of treatment; (d) quantification of $\mathrm{Co} / \mathrm{Cr}$-induced collagen gel contraction relative to control; bars indicate mean + SEM; Mann-Whitney U test was used to compare differences between control and treated group; $n=6$ from three experimental repeats; ${ }^{*} p<0.01$. (e) Matrix stiffness of collagen gel with or without $200 \mu \mathrm{M} \mathrm{Co}^{2+}$ treatment. (f) Storage modulus $\left(\mathrm{G}^{\prime}\right)$ of collagen I measured by shear rheology after $6 \mathrm{~h}$ of fibroblasts remodelling; bars represent mean + SEM; Mann-Whitney U test was used to compare differences between control and treated group; $n=6$ from three experimental repeats; ${ }^{*} p<0.01$. 
a

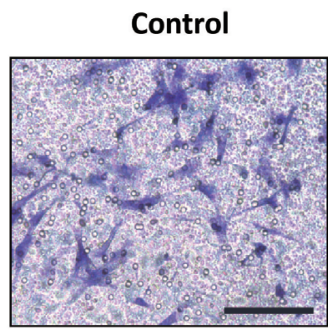

C
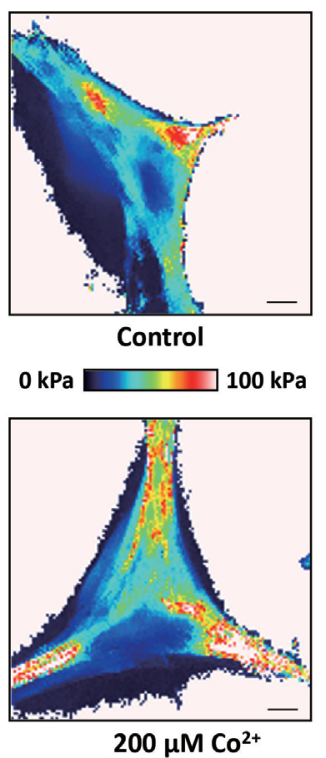

f
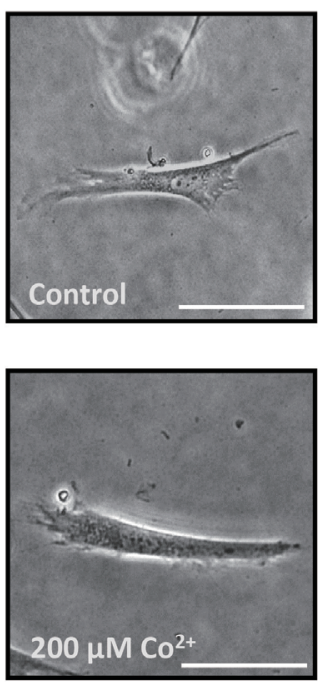

i

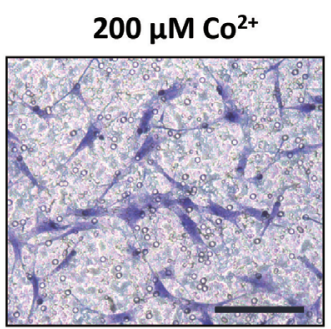

d
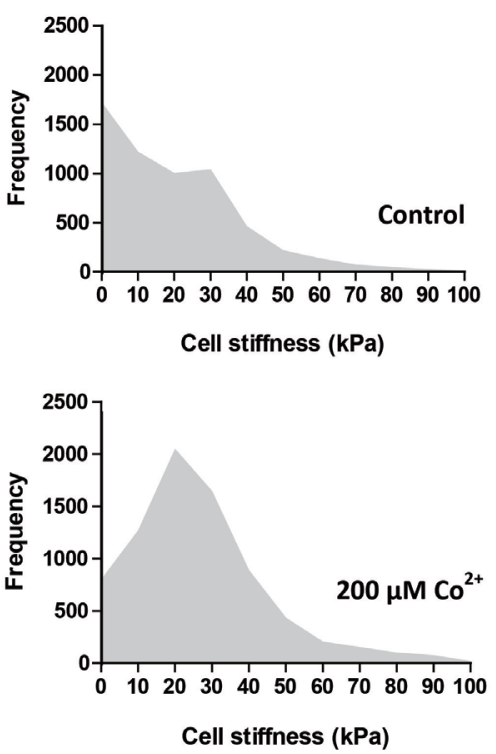

1
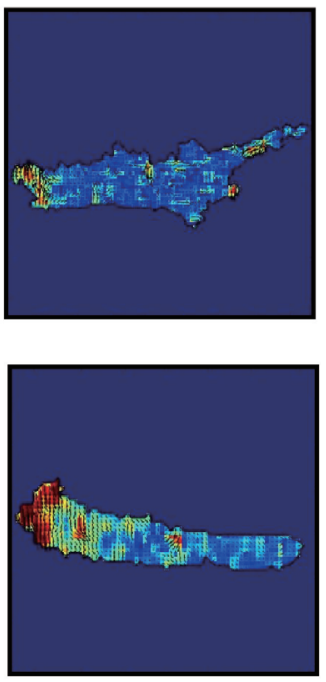

ii b

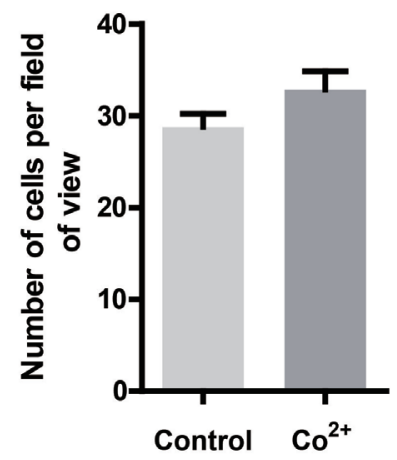

e

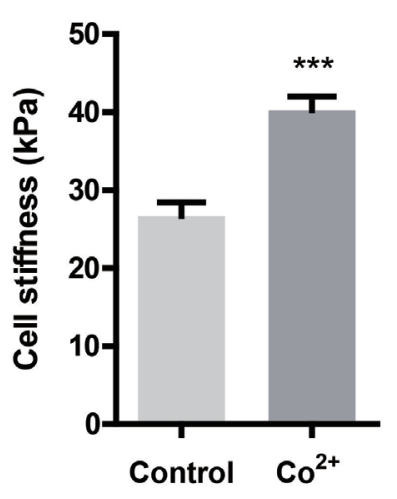

Fig. 3. Altered cellular contractile forces and cell stiffness of Co-treated fibroblasts. (a) Trans-well migration assay showing the effect of $\mathrm{Co}^{2+}$ on fibroblast migration. Scale bar: $200 \mu \mathrm{m}$. (b) Quantifications of the migration assay is based on three independent experiments. Values represent mean +SEM; $n=30$ from three independent experiments; for each experiment, 10 random fields were imaged for each treatment. (c) Representative images showing the Young's modulus of a control and of a $\mathrm{Co}^{2+}$-treated fibroblast (scale bar: $10 \mu \mathrm{m}) ;(\mathbf{d})$ associated density plot showing distribution of the measured stiffness for values of individual locations of measurement within the physiological range of $0 \mathrm{kPa}$ to $100 \mathrm{kPa}$. (e) Quantification of the mean cell stiffness of control and of $\mathrm{Co}^{2+}$-treated fibroblasts, $n=30$, Mann-Whitney $\mathrm{U}$ test; ${ }^{* * *} p<0.001$. (f) Contractile forces of a representative control and $\mathrm{CO}^{2+}$-treated fibroblast. Bright field images of individual cell (i) and corresponding stress magnitude maps (ii). Scale bar: $50 \mu \mathrm{m}$. (g) Quantification of cellular contractile force of fibroblasts from control and untreated cells; $n=30$; Mann-Whitney U test; ${ }^{* *} p<0.01$. 
the stiffness of fibroblast-populated collagen gels (data not shown).

$\mathrm{Co}^{2+}$-induced fibroblast contractility was associated with altered biomechanical properties dependent on ROS production

Effects of Co on fibroblast migration and biomechanical properties

The effect of Co on cell migration was examined, based on previous studies suggesting that collagen gel contraction may be due to an enhanced cell motility (Andujar et al., 1992). However, the current study revealed no significant effect of $200 \mu \mathrm{M} \mathrm{Co}^{2+}$ on fibroblast 3D migration, when using a trans-well migration assay (Fig. 3a,b).

The results obtained motivated a further investigation as to whether the altered cellular contractility and cytoskeleton organisation of $\mathrm{Co}^{2+}$ treated fibroblasts were associated with changes in the biomechanical properties of fibroblasts. Using a

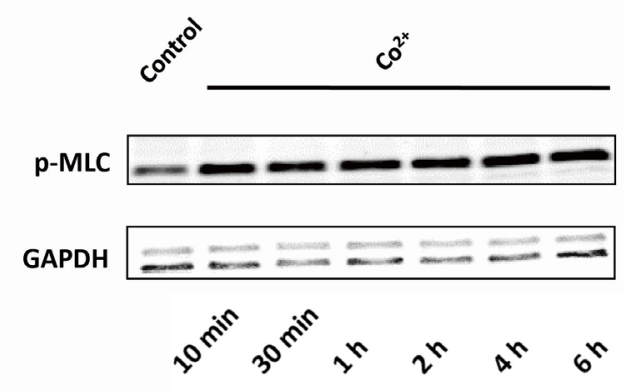

C
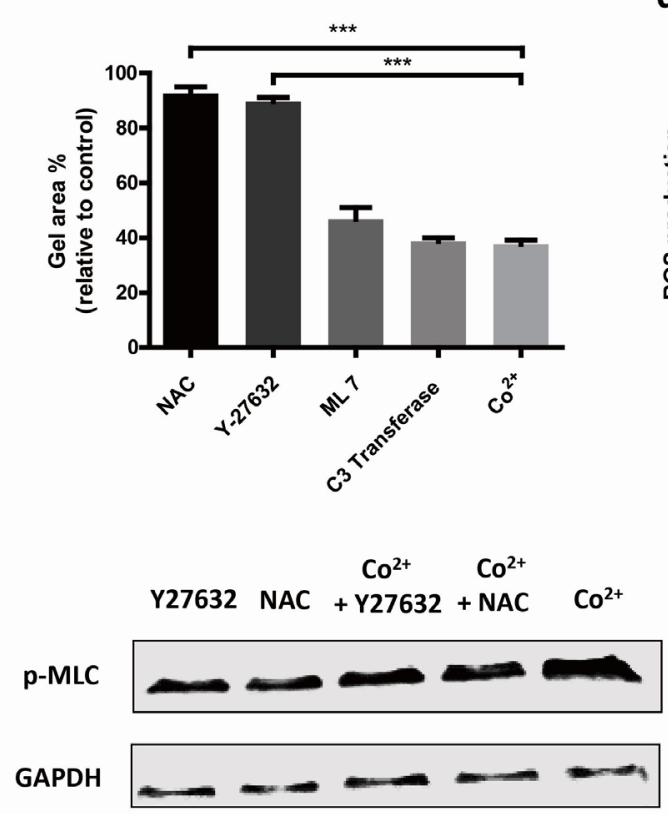

b

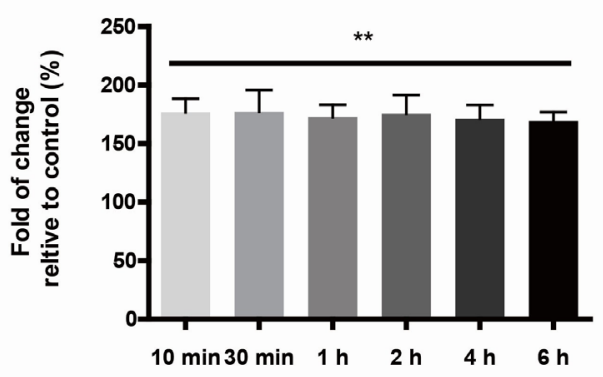

d

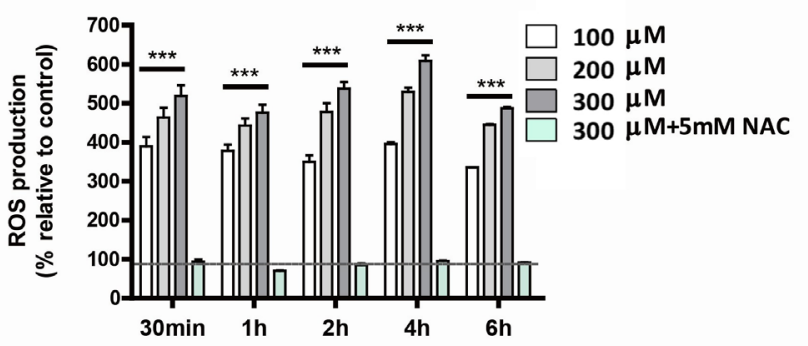

f

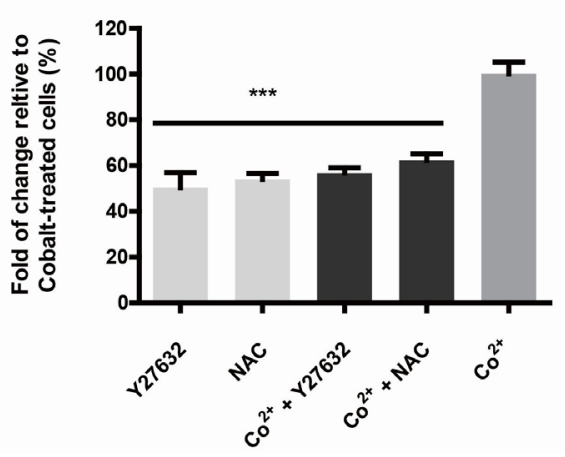

Fig. 4. $\mathrm{Co}^{2+}$-induced fibroblast activation was dependent on ROS production. (a) Phosphorylation of MLCs stimulated by $200 \mu \mathrm{M} \mathrm{Co}^{2+}$ over $6 \mathrm{~h}$ of treatment. (b) Quantification of the phosphorylation of MLCs stimulated by $200 \mu \mathrm{MCo}^{2+}$ over time. Statistically significant differences are indicated relative to untreated control based on Mann-Whitney $\mathrm{U}$ test. Values represent mean $+\mathrm{SEM} ; n=6$ from three independent experiments; ${ }^{* * *} p<0.001$. (c) The effects of the antioxidant NAC, ROCK1 inhibitor Y-27632, MLCK inhibitor ML-7 and RhoA inhibitor C3 transferase on $200 \mu \mathrm{M} \mathrm{Co}^{2+}$-mediated fibroblast-induced collagen gel contraction. Mann-Whitney U test. Values represent mean + SEM; ${ }^{* * *}$ indicates difference from cell only treated by $\mathrm{Co}^{2+}, n=6$ from 3 independent experiments $\left(2\right.$ replicates/experiment); ${ }^{* * *} p<0.01$. (d) ROS formation stimulated by 100-300 $\mu \mathrm{M} \mathrm{Co}^{2+}$ over $6 \mathrm{~h}$ of treatment and inhibition of ROS formation by NAC. Mann-Whitney U test. Values represent mean + SEM; $n=9$ from 3 independent experiments ( 3 replicates/ experiment); ${ }^{* * *}$ indicates difference from untreated cells, ${ }^{* * *} p<0.001$. (e) The effects of the antioxidant NAC and ROCK1 inhibitor Y-27632 on the phosphorylation of MLCs of fibroblast treated with $200 \mu \mathrm{M} \mathrm{Co}^{2+}$. (f) Quantification of the phosphorylation of MLCs when Y-27632 and NAC were added to the fibroblasts treated with $200 \mu \mathrm{M} \mathrm{Co}^{2+}$. Mann-Whitney U test. Values represent mean $+\mathrm{SEM} ; n=6$ from 3 independent experiments ( 2 replicates/experiment); ${ }^{* * *}$ indicates difference from $\mathrm{Co}^{2+}$-treated cells, ${ }^{* * *} p<0.001$. 
AFM and traction force microscopy, cell stiffness and contractile forces were assessed, respectively. When compared with untreated cells, $\mathrm{Co}^{2+}$-treated fibroblasts showed increased median stiffness, which was characterised by statistically significant differences in elastic moduli ( $p<0.001$, Fig. 3c-e). Representative AFM images of the cell stiffness measured from a control and a $\mathrm{Co}^{2+}$-treated fibroblast are provided in Fig. 3c, with the frequency distribution of the stiffness illustrated in Fig. 3d. According to the AFM images (Fig. 3c), the stiffest region of the $\mathrm{Co}^{2+}$-treated fibroblast mainly corresponded to the periphery of the cell, which indicated the higher density, cross-link content and better alignment of the actin at the edge of the cell as compared with untreated cells. Additionally, fibroblasts exposed to $\mathrm{Co}^{2+}$ exhibited a near 2-fold increase in cellular contractile force $(p<0.01$, Fig 3f,g).

a

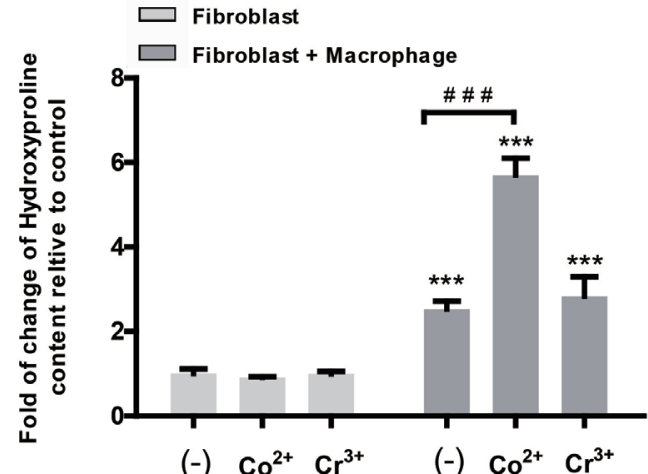

$(-) \mathrm{Co}^{2+} \mathrm{Cr}^{3+}$

$(-) \mathrm{Co}^{2+} \mathrm{Cr}^{3+}$

C
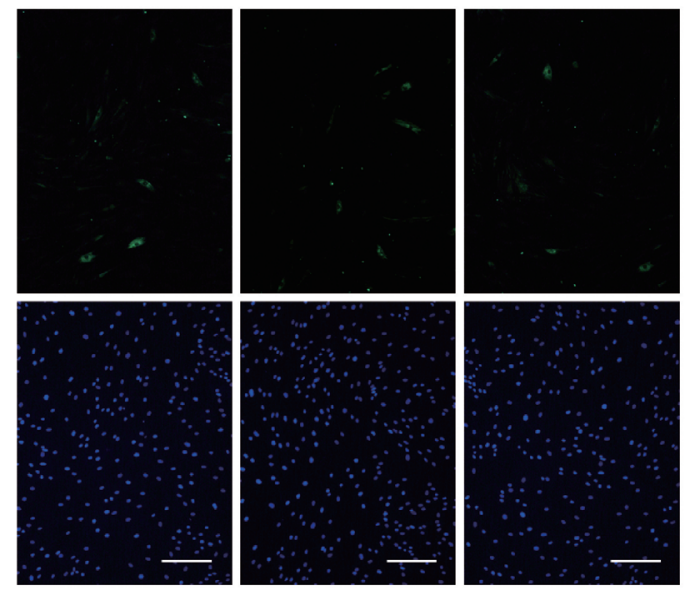

$(-)$

$\mathrm{Co}^{2+}$

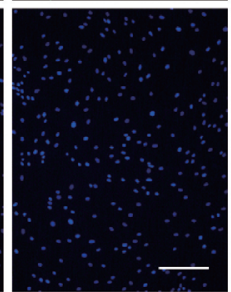

$\mathrm{Cr}^{3+}$ b

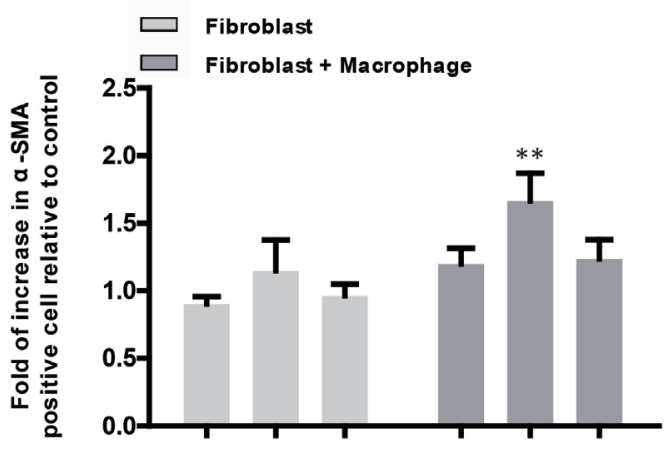

$(-) \mathrm{Co}^{2+} \mathrm{Cr}^{3+}$

(-) $\mathrm{Co}^{2+} \mathrm{Cr}^{3+}$

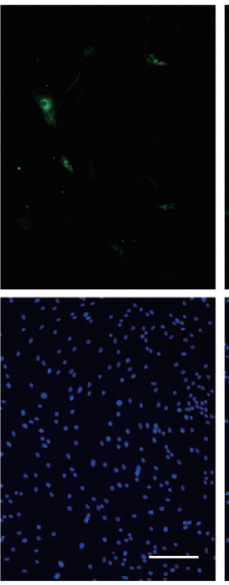

(-)
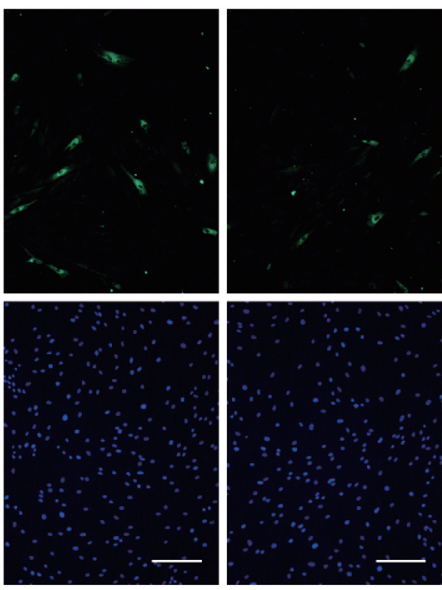

$\alpha-S M A$

$\mathrm{Co}^{2+}$

$\mathrm{Cr}^{3}$

\section{Fibroblast}

\section{Fibroblast + Macrophage}

Fig. 5. $\mathrm{Co}^{2+}$ stimulated the release of pro-fibrotic signals from macrophages. (a) Fold of change in the amount of hydroxyproline content measured in the culture medium from fibroblast when treated with $200 \mu \mathrm{M} \mathrm{Co}^{2+}, 400 \mu \mathrm{M} \mathrm{Cr}{ }^{3+}$ with or without U937 macrophages or co-culture without treatments. Values represent mean + SEM; $n=9$ from 3 independent experiments ( 3 replicates/experiment). (b) Fold of change in the percentages of $\alpha$-SMA-positive fibroblasts with different treatments as described in (a); $n=30$ from 3 independent experiments; 10 random fields were imaged for each treatment in each experiment. * indicates significant difference from untreated fibroblasts and ${ }^{\#}$ indicates difference between untreated co-culture cells and $\mathrm{Co}^{2+}$-treated co-culture cells; ${ }^{* *} p<0.01,{ }^{\# \# / * * *} p<0.001$; Mann-Whitney U test. (c) Representative images of fibroblasts with $\alpha$-SMA marker stained in each group; green: $\alpha$-SMA; blue: nucleus; scale bar: $200 \mu \mathrm{m}$. 
fibroblast-induced collagen gel contraction. ROCK1 is activated by the small GTPase Rho $A$ (Tang et al., 2012); therefore, the activity of RhoA was inhibited by treating fibroblasts during $\mathrm{Co}^{2+}$ exposure with the cell permeable RhoA inhibitor C3 transferase $(2 \mu \mathrm{g} /$ mL, Cytoskeleton, Colorado, CO, USA). However, supressing RhoA activity did not prevent collagen gel contraction (Fig. 4c). Hence, $\mathrm{Co}^{2+}$ did not induce fibroblast contraction via RhoA/ROCK1 signalling pathway, although ROCK activity was still required during this process.

Exposure to $\mathrm{Co}^{2+}$ induces ROS formation (Chandel et al., 1998; Harris and Shi, 2003; Zou et al., 2001). When cells were pre-treated for $30 \mathrm{~min}$ with a ROS inhibitor in the form of the antioxidant N-acetylcysteine (NAC, $5 \mathrm{mM}$, Sigma-Aldrich), $\mathrm{Co}^{2+}$-induced fibroblast contractility was completely prevented (Fig. 4d). Further, treatment with NAC reduced the phosphorylation of MLCs to base levels similar to that in untreated cells (Fig. 4e,f). In summary, these results suggested that $\mathrm{Co}^{2+}$ induced the activation of the fibroblast contractile phenotype by promoting MLC phosphorylation mediated through the generation of ROS.

$\mathrm{Co}^{2+}$ stimulated the release of pro-fibrotic signals from macrophages

To investigate whether $\mathrm{Co}^{2+}$-induced fibroblast contraction was accompanied by an enhanced collagen production, the amount of hydroxyproline secreted by the fibroblasts was measured following different treatments (Myllyharju and Kivirikko, 2004). $\mathrm{Co}^{2+}$ or $\mathrm{Cr}^{3+}$ alone did not have any obvious effect on pro-collagen production (Fig. 5a). However, when U937 macrophages were included in the culture and exposed to $\mathrm{Co}^{2+}$ or $\mathrm{Cr}^{3+}$, the amount of hydroxyproline content in the culture medium was significantly increased. Interestingly, co-cultures of fibroblasts and macrophages treatment with $\mathrm{Co}^{2+}$ induced a synergistic response with an increase in hydroxyproline release nearly 5 times more than in fibroblasts alone (Fig. 5a). Co-cultures treated with $\mathrm{Cr}^{3+}$ did not exhibit this synergistic effect.

$\alpha$-SMA expression, a marker of contractile and collagen-producing fibroblasts (Hinz, 2010), was also determined to assess the activation of cells exposed to $\mathrm{Co}^{2+}$ or $\mathrm{Cr}^{3+}$. The number of $\alpha$-SMA-positive fibroblasts was significantly upregulated when macrophages and fibroblasts were co-cultured in the presence of $\mathrm{Co}^{2+}$ (Fig. 5b,c). These results indicated that $\mathrm{Co}^{2+}$ stimulated the release of pro-fibrotic signals from macrophages, which enhanced the fibrotic response of fibroblasts. In contrast, $\mathrm{Cr}^{3+}$ induced no significant effects.

\section{Discussion}

Clinical reports highlight the presence of soft tissue responses, including abundant tissue necrosis and inflammatory fibrosis, in some patients with MoM implants (Bosker et al., 2015). This adverse tissue response to metals can also occur in non-MoM hip prostheses, when abnormal metal-metal contact occurs, for example when there is impingement of the acetabula cup on the trunnion (Jennings et al., 2016; Kwon et al., 2016). However, how the metal debris, whether in particulate or ionic form, causes the destruction of soft tissue remains unclear. To elucidate this mechanism, the effect of $\mathrm{Co}$ and $\mathrm{Cr}$ on human fibroblasts, the key cells involved in the fibrotic response, was investigated. No synergistic effect of Co and Cr ions on cell viability is shown in previous studies (Shah et al., 2015), therefore, this matter was not explored.

The results of the present study revealed that $\mathrm{Co}^{2+}$, but not $\mathrm{Cr}^{3+}$, significantly enhanced the fibroblast capability of contracting the ECM (tested by using type I collagen gels). The enhanced contractility was associated with an alteration in both cytoskeletal and biomechanical properties. Furthermore, $\mathrm{Co}^{2+}$ stimulated the release of pro-fibrotic signals from the macrophages, which subsequently promoted the collagen synthesis and increased the number of $\alpha$-SMA-positive fibroblasts.

Both 2D and 3D models were used to study the effects of $\mathrm{Co}^{2+}$ and $\mathrm{Cr}^{3+}$ at non-cytotoxic concentrations on human fibroblasts. An increased contraction of fibroblast-populated collagen gels was observed after treatment with $\mathrm{Co}^{2+}$. This response associated with changes in fibroblast cytoskeleton and gradually resulted in stiffer collagen matrices. Using AFM and traction force microscopy, it was shown that the altered fibroblast contractility was associated with changes in mechanical properties. $\mathrm{Co}^{2+}$ exposure produced a significant increase in cell stiffness and enhanced contractile forces. This confirmed previous observations according to which the biomechanical properties of fibroblasts serve as a key regulator of the cell's ability to organise the ECM (Humphrey et al., 2014; Rhee, 2009; Rhee and Grinnell, 2007). As an example, fibroblasts are capable of dynamically shaping the ECM due to alteration in their cytoskeleton, consequently mediating the onset and progression of cancer (Alkasalias et al., 2017).

$\mathrm{Co}^{2+}$ drove the contraction of fibroblasts by regulating MLC phosphorylation, which could be abrogated by a ROS scavenger. $\mathrm{CO}^{2+}$ leads to the generation of ROS in a range of cell types (Leonard et al., 1998). The present results indicated, for the first time, that this $\mathrm{CO}^{2+}$-induced ROS formation also played a critical role in ECM modulation by fibroblasts.

Fibroblast activation is followed by differentiation into myofibroblasts (MFs), particularly observed in conditions requiring tissue remodelling, such as wound healing and fibrosis (Eckes et al., 2000). MFs form contractile stress fibres and express de novo $\alpha$-SMA (Tomasek et al., 2002). The present study indicated that $\mathrm{Co}^{2+}$ exposure led to differentiation of HDFs by enhancing $\alpha$-SMA expression, an observation only evident during co-culture with 
macrophages. The co-culture also produced a $\mathrm{Co}^{2+}-$ induced collagen (in form of hydroxyproline) release from fibroblasts. Macrophages play a critical role in disease progression and in mediating the interplay between tissue and biomaterials. Immune cells are affected by matrix stiffness, e.g. stiffer substrates enhance both neutrophil transmigration (Stroka and Aranda-Espinoza, 2011) and release of proinflammatory cytokines by macrophages stimulated with lipopolysaccharide (Blakney et al., 2012). These observations suggest that immune cells probe and sense an alteration in the mechanical properties of the extracellular environment, hence could interact with the altered matrices through fibroblasts inducing contraction. This could explain the enhanced profibrotic response of $\mathrm{Co}^{2+}$-treated fibroblasts during macrophage co-culture.

Macrophages are capable of not only directly activating fibroblasts by releasing transforming growth factor- $\beta 1$ (TGF- $\beta 1$ ) and platelet-derived growth factor (PDGF) (Bonner et al., 1991; Wahl et al., 1990), but also controlling ECM turnover by regulating the balance of matrix metalloproteinases and their inhibitors (Fallowfield et al., 2007; Hironaka et al., 2000; Madala et al., 2010). Moreover, macrophages exacerbate fibrogenesis by producing chemokines that recruit fibroblasts and other inflammatory cells (Wynn, 2007). Furthermore, Co-treated macrophages also promote cellular $\alpha$-SMA expression, which is associated with upregulated collagen synthesis by fibroblasts as compared with $\alpha$-SMA-negative fibroblasts. Co stimulates macrophages to release a range of inflammatory mediators, such as interleukin $1 \beta$ (IL-1 $\beta$ ) and tumour necrosis factor- $\alpha$ (TNF- $\alpha$ ) (Goodman, 2007), which can affect ECM turnover and tissue homeostasis.

Total joint replacements may trigger unusual tissue remodelling (Campbell et al., 2010; Willert et al., 2005) activated by the release of metal, in particular Co ions (Savarino et al., 2002). The control of ROS can influence implant-induced fibrosis and matrix remodelling and, thereby, enhance implant performance, as evidenced by the coculture of fibroblasts with macrophages ( Fig. 5). In the present study, the effects of Co on fibroblast and macrophage-mediated ECM remodelling was explored. Activation of fibroblasts by $\mathrm{Co}$, which was exacerbated in the presence of macrophage, provided a mechanistic explanation for the excessive ECM protein deposition and aberrant matrix remodelling, with intensive infiltration of immune cells, observed in the patients with MoM hip replacement implants. In addition, ECM remodelling could also impact immune cells' behaviour and give rise to an enhanced inflammatory response, e.g. adverse tissue reaction in hip replacement. Patients with upregulated Co ions level need to be aware of a potential fibrosis response.

The limitation of this study was the use of an established fibroblast cell line rather than primary human synovial fibroblasts, which might affect the direct translation of in vitro findings to the clinical setting. The effects induced by Co would need to be further investigated in fibroblasts from patients following the implantation of MoM devices.

\section{Conclusions}

$\mathrm{Co}^{2+}$ altered cytoskeleton, contractile forces and cell stiffness of the fibroblast, inducing a profibrotic state, which was mediated by the production of ROS. Moreover, the profibrotic effect could be further enhanced by the presence of macrophages. In the light of these results, Co and macrophage acted synergistically to affect the functional properties of fibroblasts and ECM homeostasis. However, further studies are needed to determine the key mediators that govern these fibrotic reactions.

\section{Acknowledgement}

The authors are grateful to the China Scholarship Council (CSC) for their support to Jing Xu, Xiaoli Zhang and the grant from BBSRC (BB/N018532/1) for the support to Núria Gavara. We are grateful to Capital investment fund from the Institute of Bioengineering at Queen Mary University of London that was used to purchase the BioAFM used in this study.

\section{References}

Alkasalias T, Alexeyenko A, Hennig K, Danielsson F, Lebbink RJ, Fielden M, Turunen SP, Lehti K, Kashuba V, Madapura HS, Bozoky B, Lundberg E, Balland M, Guven H, Klein G, Gad AK, Pavlova T (2017) RhoA knockout fibroblasts lose tumorinhibitory capacity in vitro and promote tumor growth in vivo. Proc Natl Acad Sci U S A 114: E1413-E1421.

Andujar MB, Melin M, Guerret S, Grimaud JA (1992) Cell-migration influences collagen gel contraction. J Submicrosc Cytol Pathol 24: 145-154.

Behl B, Papageorgiou I, Brown C, Hall R, Tipper JL, Fisher J, Ingham E (2013) Biological effects of cobalt-chromium nanoparticles and ions on dural fibroblasts and dural epithelial cells. Biomaterials 34: 3547-3558.

Blakney AK, Swartzlander MD, Bryant SJ (2012) The effects of substrate stiffness on the in vitro activation of macrophages and in vivo host response to poly(ethylene glycol)-based hydrogels. J Biomed Mater Res A 100: 1375-1386.

Bonner JC, Osorniovargas AR, Badgett A, Brody AR (1991) Differential proliferation of rat lung fibroblasts induced by the platelet-derived growth factor- $\mathrm{AA}$, factor- $\mathrm{AB}$, and factor-BB isoforms secreted 
by rat alveolar macrophages. Am J Respir Cell Mol Biol 5: 539-547.

Bosker BH, Ettema HB, Van Rossum M, Boomsma MF, Kollen BJ, Maas M, Verheyen CC (2015) Pseudotumor formation and serum ions after large head metal-on-metal stemmed total hip replacement. Risk factors, time course and revisions in 706 hips. Arch Orthop Trauma Surg 135: 417-425.

Campbell P, Ebramzadeh E, Nelson S, Takamura K, De Smet K, Amstutz HC (2010) Histological features of pseudotumor-like tissues from metal-onmetal hips. Clin Orthop Relat Res 468: 2321-2327.

Catelas I, Petit A, Zukor DJ, Huk OL (2001) Cytotoxic and apoptotic effects of cobalt and chromium ions on J774 macrophages - implication of caspase-3 in the apoptotic pathway. J Mater Sci Mater Med 12: 949-953.

Chandel NS, Maltepe E, Goldwasser E, Mathieu CE, Simon MC, Schumacker PT (1998) Mitochondrial reactive oxygen species trigger hypoxia-induced transcription. Proc Natl Acad Sci U S A 95: 1171511720.

Dalal A, Pawar V, McAllister K, Weaver C, Hallab NJ (2012) Orthopedic implant cobalt-alloy particles produce greater toxicity and inflammatory cytokines than titanium alloy and zirconium alloy-based particles in vitro, in human osteoblasts, fibroblasts, and macrophages. J Biomed Mater Res A 100: 21472158.

Davda K, Lali FV, Sampson B, Skinner JA, Hart AJ (2011) An analysis of metal ion levels in the joint fluid of symptomatic patients with metal-on-metal hip replacements. J Bone Joint Surg Br 93: 738-745.

Dimitriou D, Liow MHL, Tsai TY, Leone WA, Li GA, Kwon YM (2016) Early outcomes of revision surgery for taper corrosion of dual taper total hip arthroplasty in 187 patients. J Arthroplasty 31: 15491554.

Eckes B, Zigrino P, Kessler D, Holtkötter O, Shephard P, Mauch C, Krieg T (2000) Fibroblastmatrix interactions in wound healing and fibrosis. Matrix Biol 19: 325-332.

Ennomani H, Letort G, Guerin C, Martiel JL, Cao WX, Nedelec F, De la Cruz EM, Thery M, Blanchoin L (2016) Architecture and connectivity govern actin network contractility. Curr Biol 26: 616-626.

Fallowfield JA, Mizuno M, Kendall TJ, Constandinou CM, Benyon RC, Duffield JS, Iredale JP (2007) Scar-associated macrophages are a major source of hepatic matrix metalloproteinase-13 and facilitate the resolution of murine hepatic fibrosis. J Immunol 178: 5288-5295.

Fleury C, Petit A, Mwale F, Antoniou J, Zukor DJ, Tabrizian M, Huk OL (2006) Effect of cobalt and chromium ions on human MG-63 osteoblasts in vitro: morphology, cytotoxicity, and oxidative stress. Biomaterials 27: 3351-3360.

Fukata Y, Amano M, Kaibuchi K (2001) RhoRho-kinase pathway in smooth muscle contraction and cytoskeletal reorganization of non-muscle cells. Trends Pharmacol Sci 22: 32-39.
Gavara N, Sunyer R, Roca-Cusachs P, Farre R, Rotger M, Navajas D (2006) Thrombin-induced contraction in alveolar epithelial cells probed by traction microscopy. J Appl Physiol 101: 512-520.

Goodman SB (2007) Wear particles, periprosthetic osteolysis and the immune system. Biomaterials 28: 5044-5048.

Harris GK, Shi XL (2003) Signaling by carcinogenic metals and metal-induced reactive oxygen species. Mutat Res 533: 183-200.

Hinz B (2010) The myofibroblast: paradigm for a mechanically active cell. J Biomech 43: 146-155.

Hironaka K, Sakaida I, Matsumura Y, Kaino S, Miyamoto K, Okita K (2000) Enhanced interstitial collagenase (matrix metalloproteinase-13) production of Kupffer cell by gadolinium chloride prevents pig serum-induced rat liver fibrosis. Biochem Biophys Res Commun 267: 290-295.

Humphrey JD, Dufresne ER, Schwartz MA (2014) Mechanotransduction and extracellular matrix homeostasis. Nat Rev Mol Cell Biol 15: 802-812.

Jennings JM, Dennis DA, Yang CC (2016) Corrosion of the head-neck junction after total hip arthroplasty. J Am Acad Orthop Surg 24: 349-356.

Kwon YM, Khormaee S, Lincoln MH, Tsai TY, Freiberg AA, Rubash HE (2016) Asymptomatic pseudotumors in patients with taper corrosion of a dual-taper modular femoral stem MARS-MRI and metal ion study. J Bone Joint Surg Am 98: e93.

Kreplak L (2016) Introduction to atomic force microscopy (AFM) in biology. Curr Protoc Protein Sci 85: 17.7.1-17.7.21.

Kwon YM, Lombardi AV, Jacobs JJ, Fehring TK, Lewis CG, Cabanela ME (2014) Risk stratification algorithm for management of patients with metalon-metal hip arthroplasty: consensus statement of the American Association of Hip and Knee Surgeons, the American Academy of Orthopaedic Surgeons, and the Hip Society. J Bone Joint Surg Am 96: e4. DOI: 10.2106/JBJS.M.00160.

Leonard S, Gannett PM, Rojanasakul Y, SchweglerBerry D, Castranova V, Vallyathan V, Shi X (1998) Cobalt-mediated generation of reactive oxygen species and its possible mechanism. J Inorg Biochem 70: 239-244.

Madala SK, Pesce JT, Ramalingam TR, Wilson MS, Minnicozzi S, Cheever AW, Thompson RW, MentinkKane MM, Wynn TA (2010) Matrix metalloproteinase 12-deficiency augments extracellular matrix degrading metalloproteinases and attenuates IL-13dependent fibrosis. J Immunol 184: 3955-3963.

Madl AK, Liong M, Kovochich M, Finley BL, Paustenbach DJ, Oberdorster G (2015) Toxicology of wear particles of cobalt-chromium alloy metal-onmetal hip implants part I: physicochemical properties in patient and simulator studies. Nanomedicine 11: 1201-1215.

Matharu GS, Pandit HG, Murray DW, Judge A (2016) Adverse reactions to metal debris occur with all types of hip replacement not just metalon-metal hips: a retrospective observational study 
of 3340 revisions for adverse reactions to metal debris from the National Joint Registry for England, Wales, Northern Ireland and the Isle of Man. BMC Musculoskelet Disord 17: 495.

Moussavi RS, Kelley CA, Adelstein RS (1993) Phosphorylation of vertebrate monmuscle and smooth-muscle myosin heavy-chains and lightchains. Mol Cell Biochem 128: 219-227.

Muller ME (1995) The benefits of metal-on-metal total hip replacements. Clin Orthop Relat Res: 54-59.

Myllyharju J, Kivirikko KI (2004) Collagens, modifying enzymes and their mutations in humans, flies and worms. Trends Genet 20: 33-43.

Natu S, Sidaginamale RP, Gandhi J, Langton DJ, Nargol AVF (2012) Adverse reactions to metal debris: histopathological features of periprosthetic soft tissue reactions seen in association with failed metal on metal hip arthroplasties. J Clin Pathol 65: 409-418.

Pandit H, Glyn-Jones S, McLardy-Smith P, Gundle R, Whitwell D, Gibbons CL, Ostlere S, Athanasou N, Gill HS, Murray DW (2008) Pseudotumours associated with metal-on-metal hip resurfacings. J Bone Joint Surg Br 90: 847-851.

Papageorgiou I, Brown C, Schins R, Singh S, Newson R, Davis S, Fisher J, Ingham E, Case CP (2007) The effect of nano- and micron-sized particles of cobalt-chromium alloy on human fibroblasts in vitro. Biomaterials 28: 2946-2958.

Petit A, Mwale F, Zukor DJ, Catelas I, Antoniou J, Huk OL (2004) Effect of cobalt and chromium ions on bcl-2, bax, caspase-3, and caspase- 8 expression in human U937 macrophages. Biomaterials 25: $2013-$ 2018.

Plummer DR, Berger RA, Paprosky WG, Sporer SM, Jacobs JJ, Della Valle CJ (2016) Diagnosis and management of adverse local tissue reactions secondary to corrosion at the head-neck junction in patients with metal on polyethylene bearings. J Arthroplasty 31: 264-268.

Queally JM, Devitt BM, Butler JS, Malizia AP, Murray D, Doran PP, O’Byrne JM (2009) Cobalt ions induce chemokine secretion in primary human osteoblasts. J Orthop Res 27: 855-864.

Reddy GK, Enwemeka CS (1996) A simplified method for the analysis of hydroxyproline in biological tissues. Clin Biochem 29: 225-229.

Rhee S (2009) Fibroblasts in three dimensional matrices: cell migration and matrix remodeling. Exp Mol Med 41: 858-865.

Rhee S, Grinnell F (2007) Fibroblast mechanics in 3D collagen matrices. Adv Drug Deliv Rev 59: 1299 1305.

Savarino L, Granchi D, Ciapetti G, Cenni E, Nardi Pantoli A, Rotini R, Veronesi CA, Baldini N, Giunti A (2002) Ion release in patients with metal-on-metal hip bearings in total joint replacement: A comparison with metal-on-polyethylene bearings. J Biomed Mater Res 63: 467-474.

Shah K M, Wilkinson J M, Gartland A (2015) Cobalt and chromium exposure affects osteoblast function and impairs the mineralization of prosthesis surfaces in vitro. J Orthop Res 33: 1663-1670.

Shulman RM, Zywiel MG, Gandhi R, Davey JR, Salonen DC (2015) Trunnionosis: the latest culprit in adverse reactions to metal debris following hip arthroplasty. Skeletal Radiol 44: 433-440.

Stroka KM, Aranda-Espinoza H (2011) Endothelial cell substrate stiffness influences neutrophil transmigration via myosin light chain kinasedependent cell contraction. Blood 118: 1632-1640.

Tang AT, Campbell WB, Nithipatikom K (2012) ROCK1 feedback regulation of the upstream small GTPase RhoA. Cell Signal 24: 1375-1380.

Tomasek JJ, Gabbiani G, Hinz B, Chaponnier C, Brown RA (2002) Myofibroblasts and mechanoregulation of connective tissue remodelling. Nat Rev Mol Cell Biol 3: 349-363.

Vicente-Manzanares M, Ma XF, Adelstein RS, Horwitz AR (2009) Non-muscle myosin II takes centre stage in cell adhesion and migration. Nat Rev Mol Cell Biol 10: 778-790.

WahlSM, Mccartneyfrancis N, Allen JB, Dougherty EB, Dougherty SF (1990) Macrophage production of TGF-beta and regulation by TGF-beta. Ann N Y Acad Sci 593: 188-196.

Willert HG, Buchhorn GH, Fayyazi A, Flury R, Windler M, Koster G, Lohmann CH (2005) Metal-onmetal bearings and hypersensitivity in patients with artificial hip joints. A clinical and histomorphological study. J Bone Joint Surg Am 87: 28-36.

Wynn TA (2007) Common and unique mechanisms regulate fibrosis in various fibroproliferative diseases. J Clin Invest 117: 524-529.

Zou WG, Yan MD, Xu WJ, Huo HR, Sun LY, Zheng ZC, Liu XY (2001) Cobalt chloride induces PC12 cells apoptosis through reactive oxygen species and accompanied by AP-1 activation. J Neurosci Res 64: 646-653.

\section{Discussion with Reviewer}

Mark Wilkinson: How do these findings contribute to the clinical practice in terms of metals used in joint replacement?

Authors: According to the 15th Annual Report 2018 of National Joint Registry (UK) (Web ref. 1), the number of resurfacing MoM hip replacements continues to decrease, but the MoP bearings are still the most widely used articulation. While revision rate of MoP is the lowest among the implant available, recent reports of MoP failure due to trunnionosis indicate similar adverse response to MoM (Waterson et al., 2018; additional reference), with swelling, pain and an inflammatory mass. These suggest that any joint replacements containing metal component, like cobalt alloy, could lead to similar adverse response. Identifying the mechanism of cobalt-driven adverse response can help in identifying early signs of failure and in developing new safer materials. 
Mark Wilkinson: How do the used concentrations of ions compare to those observed clinically in the synovium of patients with CoCr prostheses?

Authors: The choice of ion concentrations was based on previous work on the effect of $\mathrm{Co}$ and $\mathrm{Cr}$ on different cell lines in vitro ( Madl et al., 2015). The aim of the current study was to investigate non/cytotoxic concentrations of $\mathrm{Co}$ and $\mathrm{Cr}$ (Fig. 1). The $200 \mu \mathrm{M}$ $\mathrm{Co}^{2+}(\approx 11,786 \mu \mathrm{g} / \mathrm{L})$ is within the range of Co content detected in synovial fluid from patients with metalon-metal implants, such as 0 to $24,262 \mu \mathrm{g} / \mathrm{L}$ (Davda et al., 2011) and 11.50-64,550 $\mu \mathrm{g} / \mathrm{L}$ (Beraudi et al., 2013, additional reference).

\section{Additional Reference}

Beraudi A, Catalani S, Montesi M, Stea S, Sudanese A, Apostoli P, Toni A (2013) Detection of cobalt in synovial fluid from metal-on-metal hip prosthesis: correlation with the ion haematic level. Biomarkers 18: 699-705.

Waterson HB, Whitehouse MR, Greidanus NV, Garbuz DS, Masri BA, Duncan CP (2018) Revision for adverse local tissue reaction following metal-onpolyethylene total hip arthroplasty is associated with a high risk of early major complications. Bone Joint J 100: 720-724.

\section{Web Reference}

1. http://www.njrcentre.org.uk/njrcentre/ Reports,PublicationsandMinutes/Annualreports/ tabid/86/Default.aspx [02-10-2018]

Editor's note: The Scientific Editor responsible for this paper was Chris Evans. 